provided by the amount of cod liver oil used $(20 \mathrm{ml} /$ day $)$. Our findings confirm those of Kannel et al that smoking is associated with increased plasma fibrinogen concentrations.

We have no data elucidating the mechanism of action of fish oils on plasma fibrinogen. Studies are in progress to investigate whether there might be direct or indirect effects of long chain n-3 fatty acids on hepatocyte fibrinogen production. In line with this, we speculate to what extent supplementation with long chain $n-3$ fatty acids may fine tune monocyte macrophages to modulate their hepatocyte stimulating activities, as it is well known that $n-3$ polyunsaturated fatty acids affect pro- duction of monocyte effector molecules-for example, platelet activating factors acether.

1 Goodnight SH Jr, Harris WS, Connor WE, Illingworth DR. Polyunsaturated fatty acids, hyperlipidemia, and thrombosis. Arteriosclerosis 1982;2:87-113. 2 Kannel WB, Wolf PA, Castelli WP, D'Agostino RB. Fibrinogen and risk of cardiovascular disease. The Framingham study. JAMA 1987;258:1183-6.

3 Clauss A. Gerinnungsphysiologische Schnellmetode zur Bestimmung des Fibrinogens. Acta Haematol (Basel) 1957;17:237-46.

4 Sanders TAB, Vickers M, Haines AP. Effect on blood lipids and haemostasis of a supplement of cod-liver oil, rich in eicosapentaenoic and decosahexaenoic acids, in healthy young men. Clin Sci 1981;61:317-24.

5 Sperling RI, Robin J-L, Kylander KA, et al. The effects of N-3 polyunsaturated fatty acids on the generation of platelet-activating factor-acether by human monocytes. I Immunol 1987;139: 4186-91.

(Accepted 16 Murch 1988)

\section{Obesity and postoperative complications of abdominal operation}

\author{
John S Garrow, Eva J Hastings, Alan G Cox, \\ William R S North, Maureen Gibson, \\ Thelma M Thomas, T W Meade
}

\section{Division of Clinical Sciences, MRC Clinical Research Centre, Harrow, Middlesex HA1 3UJ John S Garrow, MD, scientific staff.}

MRC Epidemiology and Medical Care Unit, Northwick Park Hospital, Harrow, Middlesex HA1 3UJ

Eva J Hastings, SRN, nurse William R S North, PHD, scientific staff

Maureen Gibson, SRN, nurse (Ms Gibson has since died) Thelma M Thomas, MRCP, scientific staff

T W Meade, DM, director

Division of Surgery, Northwick Park Hospital, Harrow, Middlesex HA1 3UJ

Alan G Cox, MD, consultant surgeon

Correspondence to: Dr Meade. operative morbidity.

\section{Patients, methods, and results} formed a consecutive series.
Although severely obese patients do present special problems at operation, ${ }^{12}$ it is not clear whether moderate obesity significantly increases the incidence of postoperative complications and, if so, whether preoperative weight loss reduces the risk. We therefore carried out a prospective study to see whether moderate obesity was associated with increased post-

Given that about $15 \%$ of patients are obese and that the incidence of a particular complication is about $25 \%$ in non-obese patients, a total of 500 patients would give an $80 \%$ chance of detecting an increase in incidence of $15 \%$ or more-that is, an incidence of $40 \%$ or more in obese patients. Over five years we recruited 473 patients (176 men and 297 women) of whom 31 men $(18 \%)$ and 42 women (14\%) were obese according to a prespecified definition of a Quetelet index (weight/ height $^{2}$ ) of 27 or more for men and 30 or more for women. Apart from a few eligible patients who could not be included for various reasons, those recruited

Of the 473 patients, $369(78 \%)$ had cholescystectomy, $54(11 \%)$ vagotomy, $21(4 \%)$ gastrectomy, and $29(6 \%)$ small or large bowel resections (initially, only patients having cholescystectomy were included.) Preoperatively, patients were weighed, their height was recorded and skinfold thickness measured with

Incidence of wound sepsis in 469 patients. Values are numbers (percentages) of patients

\begin{tabular}{|c|c|c|c|c|c|c|}
\hline & \multicolumn{2}{|c|}{ Men } & \multicolumn{2}{|c|}{ Women } & \multicolumn{2}{|c|}{ Total } \\
\hline & $\begin{array}{c}\text { Not obese } \\
(n=144)\end{array}$ & $\begin{array}{c}\text { Obese } \\
(\mathrm{n}=31)\end{array}$ & $\begin{array}{c}\text { Not obese } \\
(\mathrm{n}=252)\end{array}$ & $\begin{array}{l}\text { Obese } \\
(n=42)\end{array}$ & $\begin{array}{c}\text { Not obese } \\
(n=396\end{array}$ & $\begin{array}{c}\text { obese } \\
(n=73)\end{array}$ \\
\hline Well healed & $98(68)$ & $19(61)$ & $200(79)$ & $23(55)$ & $298(75)$ & $42(58)$ \\
\hline Serous discharge & $36(25)$ & $5(16)$ & 35 (14) & $12(29)$ & $71(18)$ & $17(23)$ \\
\hline Stitch abscess & $1(1)$ & $2(7)$ & $3(1)$ & $1(2)$ & $4(1)$ & $3(4)$ \\
\hline Pus discharge & $9(6)$ & $5(16)$ & $14(6)$ & $6(14)$ & $23(6)$ & $11(15)$ \\
\hline
\end{tabular}

Men: $\chi^{2}=9 \cdot 08, \mathrm{df}=3, \mathrm{p}=0.028$

Women: $\chi^{2}=12 \cdot 14, \mathrm{df}=3, \mathrm{p}=0.007$

Both sexes: $\chi^{2}=14 \cdot 87, \mathrm{df}=3, \mathrm{p}=0 \cdot 002$
Holtain calipers at triceps, subscapular, and suprailiac sites. At operation the depth of subcutaneous fat was measured by the surgeon. Patients were then seen on the second, fourth, and sixth postoperative days and reviewed at an outpatient visit six weeks after operation. Sepsis of the wound and drain site was divided into three categories of severity: serous discharge, superficial infection (stitch abscess), and discharge of pus. Other possible complications included deep vein thrombosis, pulmonary embolism, chest and urinary infections, and unexplained fever.

Complete details were available for 469 of the 473 patients. The table shows that there was a significant excess of wound sepsis in the obese of both sexes, being possibly more noticeable in the women. The incidence of wound sepsis was $25 \%(98 / 396)$ in non-obese and $43 \%(31 / 73)$ in obese patients, an increase of $18 \%(95 \%$ confidence interval $5 \%$ to $30 \%$ ) in obese patients. (In those who had a cholecystectomy the difference was confined to women.) Similar results were obtained with skinfold thicknesses. No differences with obesity were found in the incidence of deep vein thrombosis and pulmonary embolism, chest and urinary tract infections, unexplained fever, or other complications reported at the outpatient visit. Seven patients, one of whom was obese, died within six weeks after operation.

\section{Comment}

We found an increased risk of postoperative morbidity in obese patients only for the occurrence of wound infection. If knowledge of a patient's obesity had resulted in a tendency to overreport complications in obese patients, a difference in complications other than wound sepsis would also be expected.

Despite the increase in wound infection in obese patients we conclude that the degree of increased morbidity associated with moderate obesity is so small that it would not be practicable to study the benefit of planned preoperative weight loss in moderately obese patients and that probably little is to be gained in attempting preoperative weight loss in this group of patients.

We thank colleagues at Northwick Park for permission to include their patients in the study.

1 Harman EM, Block AJ. Why does weight loss improve the respiratory insufficiency of obesity? Chest 1986;90:153-4.

2 Kozol RA, Fromm D, Ackerman NB, Chung R. Wound closure in obese patients. Surg Gynecol Obstet 1986;162:442-4.

(Accepled 28 March 1988) 